\title{
Root Caries in an Optimally Fluoridated and a High-fluoride Community*
}

\author{
B.A. BURT, A.I. ISMAIL ${ }^{1}$, and S.A. EKLUND
}

Program in Dental Public Health, School of Public Health, The University of Michigan, Ann Arbor, Michigan 48109

\begin{abstract}
The purpose of this study was to measure the prevalence and distri. bution of root caries in two New Mexico communities. One community, Deming, had a natural fluoride concentration of $0.7 \mathrm{mg} / \mathrm{L}$ in its drinking water, optimum for its climate. The other, Lordsburg, was naturally fluoridated at $3.5 \mathrm{mg} / \mathrm{L}$, five times the optimum. Dental examinations were carried out on 151 adults in Deming (mean age, 39.8 years) and 164 in Lordsburg (mean age, 43.2 years); only persons born in the communities were included. Prevalence of root caries was $23.8 \%$ in Deming and $7.3 \%$ in Lordsburg; mean number of lesions was 0.69 in Deming and 0.08 in Lordsburg $(p<0.0001)$. Although there was more gingival recession in Lordsburg, Root Caries Index scores were five times greater in Deming. Root caries was more prevalent in older age groups, and was correlated with coronal caries experience in both communities. Root caries was correlated with plaque and calculus scores in Deming only. Logistic regression showed that city of residence was the major predictor of root caries, with other significant predictors being age, education, gingival recession, and loss of periodontal attachment. When combined with previous research, these results confirm that root caries experience is directly related to the fluoride concentration in the drinking water.
\end{abstract}

J Dent Res 65(9):1154-1158, September, 1986

\section{Introduction.}

Root caries is receiving increased attention as the population ages and tooth retention into later years improves, but its pathology remains incompletely understood. There have been too few epidemiological studies to define its natural history, its distribution in the population, and associated risk factors other than age and gingival recession.

Reviews of the topic in the early 1970's indicated that little information was available (Hazen et al., 1973; Jordan and Sumney, 1973). Several studies around that time on non-representative populations showed that from $39-56 \%$ of adults examined had root caries, and the mean number of lesions per person varied from 1.14 to 1.88 (Hazen et al., 1972; Chilton et al., 1972; Sumney et al., 1973). These authors reported that prevalence increased with age, and appeared to be associated with gingival recession. Root caries was virtually the only form of caries seen in an aboriginal population in Papua-New Guinea (Schamschula et al., 1974).

More recent reports have tended to confirm these earlier findings (Banting et al., 1980; Katz et al., 1982; Vehkalahti et al., 1983; Beck et al., 1985). Reviews (Katz, 1981, 1985; Nyvad and Fejerskov, 1982) lead to the conclusion that approximately $15 \%$ of all teeth with gingival recession are attacked by root caries, and that the mean number of teeth attacked per person is about 2.8. The increase in numbers of root caries lesions in older age groups is noted in all reports, though there is less agreement on the most commonly-attacked tooth sites. Gross prevalence is estimated to be from $20-40 \%$ of adults (Katz, 1985).

Received for publication March 27, 1986

Accepted for publication May 12, 1986

*This study was supported by NIDR contract no. DE 32443

${ }^{1}$ Present address: Department of Community Dentistry, Faculty of Dentistry, McGill University, 3640 University St., Montreal, Quebec, Canada H3A 2B2
The availability of fluoride is a major determinant of coronal caries, so it is natural to investigate whether fluoride has the same effects on root caries. The subject has been reported only from the Stratford-Woodstock study in Canada. Adults (average age, 40.2 years) examined in naturally-fluoridated Stratford (1.6 mg F/L), had 0.64 root lesions per person, compared with 1.36 lesions per person in non-fluoridated Woodstock, where the mean age of those examined was 42.8 years (Stamm and Banting, 1980). Stratford residents had a significantly higher fluoride content of cementum when compared with residents of non-fluoridated Chatham (Banting and Stamm, 1982). A greater understanding of fluoride's effect on root caries will assist in prevention and control of this condition, which is likely to become a greater problem in the future (Douglass and Gammon, 1984; Burt, 1985; Katz, 1985).

This paper describes the epidemiology of root caries in two naturally-fluoridated communities in rural New Mexico. The study was part of a broader assessment of the effects of high levels of fluoride in the drinking water on several aspects of oral health.

\section{Materials and methods.}

The study communities were Lordsburg and Deming, New Mexico. Lordsburg's drinking water supply averages $3.5 \mathrm{mg}$ $\mathrm{F} / \mathrm{L}$, or five times the optimum for its climatic zone. Deming's water supply averages $0.7 \mathrm{mg} \mathrm{F} / \mathrm{L}$, which is considered optimum for the area.

The two communities are about $100 \mathrm{~km}$ apart in the southern part of the state. Climate and altitude are similar, as are income levels. The 1980 census listed Deming's population as 9,964 and Lordsburg's as 3,195, although the populations of the two cities were much closer together in the $1930-50$ period, when many of the subjects in the study population were born.

Locally-based and experienced organizers, familiar with their communities, assisted in recruiting adult participants for the study. The principal criteria for selection were that participants be born in the community and had lived there throughout the period of tooth calcification, with only limited absences $(e, g$., military service) in adulthood. Water histories were carefully taken and examined against water supply records to ensure that participants were consuming city water supplies. An attempt was made to recruit the entire eligible population of each community - a feasible goal in such small towns, where the recruiters "knew everybody". Eligible adults were offered a small compensation for agreeing to be dentally examined; this helped keep refusals to a minimum. In Deming there were 189 dentate participants, in Lordsburg 187. Analysis in this paper is restricted to 151 adults in Deming and 164 in Lordsburg, aged from 27-65, from whom unequivocal water-ingestion histories were obtained, and for whom all personal and clinical data were available. Table 1 describes the examined populations.

Criteria for root caries were those described by Banting et al. (1980). Lesions were considered root caries if they were entirely or predominantly located on the root surface. When a lesion involved both the coronal and root surfaces, the examiner judged where the lesion had commenced. Softness and 
TABLE 1

DEMOGRAPHIC DATA FOR PARTICIPANTS IN THE LORDSBURG-DEMING STUDY ON ROOT CARIES

\begin{tabular}{|c|c|c|c|c|}
\hline & \multicolumn{2}{|c|}{$\begin{array}{l}\text { Lordsburg } \\
(\mathrm{n}=164)\end{array}$} & \multicolumn{2}{|c|}{$\begin{array}{c}\text { Deming } \\
(n=151)\end{array}$} \\
\hline & $\mathbf{n}$ & $\%$ & $\mathbf{n}$ & $\%$ \\
\hline Male & 54 & 32.9 & 48 & 31.8 \\
\hline Female & 110 & 67.1 & 103 & 68.2 \\
\hline Hispanic & 147 & 89.6 & 112. & 74.2 \\
\hline High School Graduates & 104 & 63.4 & 123 & 81.5 \\
\hline \multicolumn{5}{|l|}{ Age distribution: } \\
\hline $27-40$ years & 81 & 49.4 & 87 & 57.6 \\
\hline $41-50$ years & 37 & 22.6 & 46 & 30.5 \\
\hline $51-65$ years & 46 & 28.0 & 18 & 11.9 \\
\hline Mean Age: & 43.2 & years & 39.8 & years \\
\hline Mean No. of Teeth & 27.0 & & 27.1 & \\
\hline
\end{tabular}

discoloration were the main features which distinguished root lesions from cervical abrasion. All teeth present were examined for root caries and root-surface restorations, whether gingival recession was present or not. Tooth surfaces were dried when there was reason to believe that a lesion might be present, and calculus was carefully removed when necessary.

Periodontal conditions, plaque, and calculus were recorded on the six index teeth defined by Ramfjord (1959). These teeth are the maxillary right first molar, left central incisor, and left first pre-molar; the mandibular left first molar, right central incisor, and right first pre-molar. Index teeth were chosen, rather than full-mouth examinations, because it was considered that sufficient information for this study could be obtained from partial recording while minimizing time added to what was already a lengthy clinical examination. Given that periodontal and oral hygiene data were to be based on only six teeth, a substitution rule for missing index teeth was applied to ensure complete data as far as possible. When an index tooth was missing, the first substitute was the contralateral tooth, the second was an adjacent tooth of the same type, the third was a contralateral tooth of the same type.

Loss of periodontal attachment was measured by Ramfjord's method (1959), and gingival recession was recorded if at least $1 \mathrm{~mm}$ of root surface was visible between the gingival crest and the cemento-enamel junction. Calculus was scored as 2 if subgingival calculus was present, as 1 if only supragingival calculus was present, and zero for no calculus. Plaque was recorded on the six index teeth according to the criteria of Silness and Löe (1964). Again, it was considered that scoring plaque on index teeth, rather than on all teeth in the mouth, as originally described, would still provide data sufficiently sensitive for the purposes of this study without adding unduly to examination time.

\section{Results.}

There were 36 persons with one or more root caries lesions in Deming $(23.8 \%)$ and 12 such persons in Lordsburg (7.3\%). There is a substantial difference in age prevalence between the cities, as shown in Table 2 . In both communities, there were no significant differences in root caries distribution by gender or by income levels (data not shown).

The mean number of lesions per person examined was 0.08 in Lordsburg and 0.69 in Deming ( $p<0.0001$ ). For persons with root caries, means were 1.08 lesions per person in Lordsburg and 2.89 lesions per person in Deming $(\mathrm{p}=0.04)$. Table 3 shows the mean number of root caries lesions per person for the three age groups, and for those persons affected by root
TABLE 2

NUMBERS OF PERSONS WITH ROOT CARIES, BY AGE, IN LORDSBURG AND DEMING, NM

\begin{tabular}{|c|c|c|c|c|c|c|c|}
\hline \multirow[b]{2}{*}{ Age } & \multicolumn{3}{|c|}{ Lordsburg } & \multicolumn{3}{|c|}{ Deming } & \multirow[b]{2}{*}{$\mathrm{p}^{*}$} \\
\hline & $\mathbf{n}$ & $\begin{array}{c}\text { No. with } \\
\text { Root Caries }\end{array}$ & $\%$ & $\mathbf{n}$ & $\begin{array}{c}\text { No. with } \\
\text { Root Caries }\end{array}$ & $\%$ & \\
\hline $27-40$ & 81 & 3 & 3.7 & 87 & 10 & 11.5 & 0.11 \\
\hline $41-50$ & 37 & 2 & 5.4 & 46 & 16 & 34.8 & 0.001 \\
\hline $51-65$ & 46 & 7 & 15.2 & 18 & 10 & 55.6 & 0.001 \\
\hline Total & $\overline{164}$ & $\overline{12}$ & 7.3 & $\overline{151}$ & 36 & 23.8 & 0.0001 \\
\hline
\end{tabular}

TABLE 3

MEAN NUMBERS OF ROOT CARIES LESIONS BY AGE FOR ALL PERSONS, AND FOR THOSE WITH ROOT CARIES, LORDSBURG AND DEMING, NM

\begin{tabular}{|c|c|c|c|c|c|}
\hline \multicolumn{3}{|c|}{ Lordsburg } & \multicolumn{3}{|c|}{ Deming } \\
\hline \multicolumn{6}{|c|}{ All persons $(n=315)$} \\
\hline Age & $\mathrm{n}$ & Root lesions & $\mathrm{n}$ & Root lesions & $\mathrm{p}^{*}$ \\
\hline $27-40$ & 81 & 0.04 & 87 & 0.15 & 0.05 \\
\hline $41-50$ & 37 & 0.05 & 46 & 1.35 & 0.004 \\
\hline $51-65$ & 46 & 0.17 & 18 & 1.61 & 0.005 \\
\hline Total & $\overrightarrow{164}$ & $\overline{0.08}$ & $\overline{151}$ & $\overline{0.69}$ & 0.0000 \\
\hline \multicolumn{6}{|c|}{ Persons with root caries $(n=48)$} \\
\hline $27-40$ & 3 & 1.00 & 10 & 1.30 & (n too small) \\
\hline $41-50$ & 2 & 1.00 & 16 & 3.88 & (n too small) \\
\hline $51-65$ & 7 & 1.14 & 10 & 2.90 & 0.14 \\
\hline Total & 12 & $\overline{1.08}$ & 36 & $\overline{2.89}$ & $\overline{0.04}$ \\
\hline
\end{tabular}

* Two-sample $t$-test.

TABLE 4

DISTRIBUTION OF ROOT CARIES LESIONS BY TOOTH TYPE, LORDSBURG AND DEMING, NM

\begin{tabular}{lcr}
\hline \multicolumn{1}{c}{ Tooth Type } & Lordsburg & Deming \\
\hline Maxilla: & & \\
Third molar & 1 & 1 \\
Second molar & 1 & 7 \\
First molar & - & 11 \\
Second pre-molar & 1 & 5 \\
First pre-molar & 2 & 13 \\
Cuspid & 3 & 9 \\
Lateral & 1 & 4 \\
Central & & 1 \\
Mandible: & - & \\
Third molar & 1 & 2 \\
Second molar & - & 10 \\
First molar & 1 & 11 \\
Second pre-molar & 1 & 10 \\
First pre-molar & 1 & 17 \\
Cuspid & - & 3 \\
Lateral & - & - \\
Central & 13 & 104 \\
Total lesions: & & \\
\hline
\end{tabular}

caries. Table 4 gives the distribution of lesions by tooth type; no clear-cut pattern emerges from these data.

The Root Caries Index (Katz, 1980) expresses the mean number of root caries lesions per person as a proportion of the number of teeth with recession. Table 5 shows that although there was more gingival recession in Lordsburg, the Root Caries Index (RCI) score was over five times greater in Deming. When the RCI was derived only for those 12 persons in Lordsburg and 36 in Deming who had root caries, the RCI scores were $16.7 \%$ in Lordsburg and $28.0 \%$ in Deming $(\mathrm{p}=0.17)$.

Root caries was correlated with coronal caries, as shown in Table 6 . In both cities, persons with root caries tended to have 
TABLE 5

MEAN NUMBER OF TEETH WITH RECESSION ${ }^{1}$, AND ROOT CARIES INDEX VALUES ${ }^{2}$, LORDSBURG AND DEMING, NM

\begin{tabular}{lccl}
\hline \hline & Lordsburg & Deming & $\mathrm{p}^{3}$ \\
\hline No. Persons Examined & 164 & 151 & \\
Mean No. Teeth with & & & \\
$\quad$ Recession & 8.14 & 6.04 & 0.01 \\
Roet Caries Index & $1.22 \%$ & $6.68 \%$ & 0.0002 \\
\hline
\end{tabular}

${ }^{1}$ At least $1 \mathrm{~mm}$ between the gingival crest and the cemento-enamel junction.

${ }^{2} \mathrm{Katz}(1980)$

${ }^{3}$ Two-sample $t$-test.

TABLE 6

CORONAL DMFT SCORES FOR PERSONS WITH AND WITHOUT ROOT CARIES, LORDSBURG AND DEMING, NM

\begin{tabular}{lccccc}
\hline \hline & \multicolumn{2}{c}{ Lordsburg } & & Deming \\
\cline { 2 - 5 } \cline { 5 - 6 } Root caries & $\mathrm{n}$ & Mean DMFT & & $\mathrm{n}$ & Mean DMFT \\
\hline No & 152 & 9.2 & 115 & 10.7 \\
Yes & 12 & 14.3 & & 36 & 14.8 \\
& & $\left(\mathrm{p}^{*}=0.004\right)$ & & $\left(\mathrm{p}^{*}=0.001\right)$ \\
\hline
\end{tabular}

*One-way ANOVA.

TABLE 7

MEAN PLAQUE AND CALCULUS SCORES FOR PERSONS WITH AND WITHOUT ROOT CARIES, LORDSBURG AND DEMING, NM

\begin{tabular}{lcrcc}
\hline & Root caries & $\mathrm{n}$ & Plaque $^{1}$ & Calculus $^{2}$ \\
\hline Lordsburg: & No & 152 & 0.45 & 1.95 \\
& Yes & 12 & 0.65 & 2.00 \\
& & & $(\mathrm{p}=0.08)^{3}$ & $(\mathrm{p}=0.28)$ \\
Deming: & No & 115 & 0.24 & 1.76 \\
& Yes & 36 & 0.39 & 1.93 \\
& & & $(\mathrm{p}=0.01)$ & $(\mathrm{p}=0.01)$ \\
\hline
\end{tabular}

${ }^{1}$ Silness and Löe (1964); recorded on six index teeth.

${ }^{2}$ Ramfjord (1959); recorded on six index teeth.

${ }^{3}$ One-way ANOVA.

more coronal decay and fewer fillings, suggesting that they received less dental care.

In Deming, plaque and calculus scores were significantly associated with root caries, but a similar association could not be demonstrated in Lordsburg (Table 7). The lack of a statistically significant association between calculus scores and root caries in Lordsburg stemmed from the near-universality of subgingival calculus in persons examined there. However, there was a correlation between gingival recession and the presence of subgingival calculus (Spearman's $r=0.23$ ), which may have confounded these relationships. Accordingly, a logistic regression model was developed to examine these potentially confounding effects. The dependent variable in the model was dichotomous, with the first level being the person with no root lesions, the second level the person with at least one root lesion. This model included as predictor variables city, age, gender, ethnicity, number of teeth, number of teeth with recession, presence of plaque, presence of subgingival calculus, and loss of periodontal attachment. The model confirmed that city of residence was still the strongest predictor of root caries (ratio of coefficient to standard error $=5.06$ ), with age, gingival recession, and loss of periodontal attachment lesser but also significant predictors. Table 8 displays the data from the logistic regression model. Logistic regression was chosen over linear regression because of the skewed distribution of root caries, but similar results were obtained with a linear regression model.

The odds ratio for root caries by city was 3.26 , showing
TABLE 8

RELATIONSHIP OF PRESENCE OF ROOT CARIES TO SELECTED VARIABLES, LORDSBURG AND DEMING, NM

\begin{tabular}{|c|c|c|c|}
\hline Dependent Variable & \multicolumn{3}{|c|}{ Logistic Regression Statistics } \\
\hline $\begin{array}{l}\text { Root caries (no: yes) } \\
\text { Independent Variables }\end{array}$ & Coefficient & Standard Error & Ratio \\
\hline City of residence & 2.58 & 0.51 & $5.06^{* *}$ \\
\hline Age & 0.07 & 0.03 & $2.65^{*}$ \\
\hline Gender & 0.68 & 0.46 & 1.49 \\
\hline Ethnicity & 0.02 & 0.52 & 0.04 \\
\hline Years of education & 0.50 & 0.26 & $1.96^{*}$ \\
\hline Number of teeth & -0.03 & 0.05 & 0.67 \\
\hline Mean no. of teeth with recession & 0.08 & 0.03 & $2.31 *$ \\
\hline Mean plaque score & -0.13 & 0.64 & -0.20 \\
\hline Mean calculus score & 1.60 & 1.15 & 1.39 \\
\hline Mean loss of periodontal attachment & 0.38 & 0.18 & $2.14 *$ \\
\hline
\end{tabular}

$* * \mathrm{p}<0.01$

$*_{\mathrm{p}}<0.05$.

that a resident of Deming was 3.26 times more likely to have root caries than a resident of Lordsburg.

\section{Discussion.}

The way in which participants were chosen for this study ensured that virtually all adults who were essentially wholelife residents were contacted. Refusals were few, so we believe that the groups closely represented the long-term residents of the two communities and could therefore be compared validly. Repeat examinations showed that examiner reliability was satisfactory (Ismail et al., 1985). Some lesions in heavily-fluorosed teeth in Lordsburg were difficult to detect; if some lesions were thereby missed, then the differences between the two communities would appear greater than they really were. However, results of the reliability tests suggest that it is unlikely that results were affected by diagnostic errors.

Gross prevalence of root caries in the New Mexico communities was lower than that generally reported elsewhere. Deming's prevalence of $23.8 \%$ barely came within the range of Katz's estimate of $20-40 \%$ of all adults, and the Lordsburg prevalence of $7.3 \%$ was much lower. Results from the Iowa study (Beck et al., 1985) disclosed that each adult averaged 2.3 root lesions, again much higher than the 0.08 lesions per person in Lordsburg and 0.69 in Deming. The Iowa population, however, was considerably older than these New Mexico groups and had little exposure to fluoridated water.

The comparison of greatest interest is that between Deming and Stratford, Ontario, which is naturally fluoridated at 1.6 $\mathrm{mg} / \mathrm{L}$. Stamm and Banting (1980) reported that adults whose mean age was 40.2 years in Stratford averaged 0.64 root lesions. This figure is almost the same as that recorded in Deming, where average age was 39.8 years and root lesions averaged 0.69 . Stratford's fluoride concentration is slightly above optimum, and Deming's is considered optimum for its climate, so there is a remarkable consistency in these results.

Root caries was correlated with coronal caries, confirming the finding of Banting et al. (1980) from a cross-sectional study, but differing from the correlation found by the same investigators in a longitudinal assessment (Banting et al., 1985). It thus remains uncertain whether the risk factors in coronal caries are similar to those for root caries.

The Root Caries Index (RCI), described by Katz (1980), presents the number of root lesions as a proportion of the number of teeth with recession, and thus provides an attack rate. The RCI scores in this study (Table 5) were, again, lower than the estimated RCI of $11.4 \%$ for the general population 
(Katz et al., 1982). The RCI was five times greater in Deming than in Lordsburg (Table 5), yet when the RCI was applied only to persons with root caries, this difference was reduced to less than two-fold, and was not statistically significant. Because the number of teeth with recession was greater in Lordsburg than in Deming (Table 5), this suggests that the protective effect of fluoride might be greater in preventing otherwisesusceptible persons from getting the condition in the first place, rather than in reducing the number of teeth affected once root caries was present. This issue calls for further investigation.

The $\mathrm{RCI}$ is based on the assumption that gingival recession is a pre-condition for root caries, yet six of the 48 root lesions recorded in this study $(12.5 \%)$ were on teeth with no recession. Obviously, root caries canno: occur on teeth which have not lost some periodontal attachment and therefore have not exposed the root surface to the oral environment, but this finding can be explained partly by the criterion for determining recession (that at least $1 \mathrm{~mm}$ of root surface must be visible between the gingival crest and the cemento-enamel junction) and partly by the poor gingival health of the groups examined. Severe gingivitis was common, so that a number of teeth where loss of attachment had occurred had such swollen gingivae that recession could not be recorded.

Since an unequivocal difference in root caries prevalence was observed between the two communities, attributable to the different fluoride concentrations in the drinking waters, it remains to investigate whether the action of the fluoride was predominantly systemic or topical. Banting and Stamm (1982) have proposed a systemic action, based on their finding a higher concentration of fluoride in the cementum of teeth from fluoridated Stratford than in that from non-fluoridated Chatham. They were careful to test cementum from the middle sections of the root surfaces, very little of which would have been exposed to the oral environment. Our comparison between Lordsburg and Deming was a little different from those in the Canadian studies: The New Mexico communities were highfluoride and optimum-fluoride rather than optimum-fluoride and low-fluoride, so it is not certain whether the same relative differences apply. This is a subject for further research.

If fluoride is continuously deposited in unexposed cemental surfaces throughout life, as Banting and Stamm (1982) have stated, then the later that root surfaces become exposed to the oral environment, the better-protected they should be. In this systemic model, the risk of root caries developing would then become a function of lifetime fluoride intake as well as of the age at which root surfaces become exposed, i.e., the age at which gingival recession occurs.

A topical cariostatic action of fluoridated drinking water in enamel caries has been demonstrated in human populations (Hardwick et al., 1982), presumably from remineralization action (Fejerskov et al., 1981). It could be postulated that a topical effect also operates with respect to root caries. If it does, the results of this study suggest that it operates better at above-optimum concentrations of fluoride. Katz's observation (1985) - that RCI values are much the same in each decade of life from 20 to 80 - suggests that root caries is not a function of age per se, but rather of exposure of root surfaces. In this study, the age at which recession developed could not be determined, but because there was more recession in Lordsburg, it may have developed earlier there. If so, the lower prevalence of root caries in Lordsburg might indicate some topical protective effect. So, while the evidence from Stratford and from this study clearly indicates a protective benefit of fluoridated water with respect to root caries development, we cannot determine whether the benefit is primarily systemic or topical.

This study confirms the earlier work of Stamm and Banting
(1980), who found that fluoridated water is associated with a lower prevalence of root caries. The similarity of results in Stratford and Deming, however, adds another dimension to that conclusion, because a clear rank-ordering of root caries prevalence by water fluoride concentration can be seen. Root caries prevalence is worst in non-fluoridated Woodstock, better in near-optimum Stratford and optimum Deming, and lowest in five-times-optimum Lordsburg. While fluoridation of drinking waters at five times the optimum concentration to prevent root caries obviously cannot be recommended, this study does offer promising avenues for further research on prevention of root caries by fluoride.

\section{REFERENCES}

BANTING, D.W.; ELLEN, R.P.; and FILLERY, E.D. (1980): Prevalence of Root Surface Caries among Institutionalized Older Persons, Community Dent Oral Epidemiol 8:84-88.

BANTING, D.H.; ELLEN, R.P.; and FILLERY, E.D. (1985): A Longitudinal Study of Root Caries: Baseline and Incidence Data, $J$ Dent Res 64:1141-1144

BANTING, D.W. and STAMM, J.W. (1982): Effects of Age and Length of Exposure to Fluoridated Water on Root Surface Fluoride Concentration, Clin Prev Dent 4:3-7.

BECK, J.D.; HUNT, R.J.; HAND, J.S.; and FIELD, H.M. (1985): Prevalence of Root and Coronal Caries in a Noninstitutionalized Older Population, J Am Dent Assoc 111:964-967.

BURT, B.A. (1985): The Future of the Caries Decline, J Pub Health Dent 45:261-269.

CHILTON, N.W.; HAZEN, S.P.; and MUMMA, R.D., Jr. (1972): The Problem of Root Caries. I. Clinical Lesion, IADR Progr \& Abst 51:No. 685.

DOUGLASS, C.W. and GAMMON, M.D. (1984): The Epidemiology of Dental Caries and Its Impact on the Operative Dentistry Curriculum, $J$ Dent Educ 48:547-555.

.FEJERSKOV, O.; THYLSTRUP, A.; and LARSEN, M.J. (1981): Rational Use of Fluorides in Caries Prevention, Acta Odontol Scand 39:241-249.

HARDWICK, J.L.; TEASDALE, J.; and BLOODWORTH, G. (1982): Caries Increments over 4 Years in Children Aged 12 at the Start of Water Fluoridation, Br Dent $J$ 153:217-222.

HAZEN, S.P.; CHILTON, N.W.; and MUMMA, R.D., Jr. (1972): The Problem of Root Caries. 3. A Clinical Study, IADR Progr \& Abst 51:No. 689.

HAZEN, S.P.; CHILTON, N.W.; and MUMMA, R.D., Ir. (1973): The Problem of Root Caries. I. Literature Review and Clinical Description, J Am Dent Assoc 86:137-144.

HAZEN, S.P.; CHILTON, N.W.; and RAPPAPORT, H.M. (1974): Root Surface Caries. IV. Surface Distribution in Two Large Population Groups, IADR Progr \& Abst 53:No. 798.

ISMAIL, A.I.; EKLUND, S.A.; BURT, B.A.; and CALDERONE, J.J. (1985): Intraexaminer Reliability of 11 Dental Measurements, IADR Progr \& Abst 64:No. 1706.

JORDAN, H.V. and SUMNEY, D.L. (1973): Root Surface Caries: Review of the Literature and Significance of the Problem, $J$ Per. iodontol 44:158-163.

KATZ, R.V. (1980): Assessing Root Caries in Populations: the Evolution of the Root Caries Index, J Publ Health Dent 40:7-16.

KATZ, R.V. (1981): Root Caries: Clinical Implications of the Current Epidemiologic Data, Northwest Dent 60:306-310.

KATZ, R.V. (1985): Root Caries--Is It the Problem of the Future?, $J$ Can Dent Assoc 51:511-514.

KATZ, R.V.; HAZEN, S.P.; CHILTON, N.W.; and MUMMA, R.D. (1982): The Prevalence and Intra-oral Distribution of Root Caries in an Adult Population, Caries Res 16:265-272.

NYVAD, B. and FEJERSKOV, O. (1982): Root Surface Caries: Clinical, Histopathological and Microbiological Features and Clinical Implications, Int Dent $J$ 32:311-326.

RAMFJORD, S.P. (1959): Indices for Prevalence and Incidence of Periodontal Disease, J Periodontol 30:51-59.

SCHAMSCHULA, R.G.; BARMES, D.E.; KEYES, P.H.; and GUL- 
BINAT, W. (1974): Prevalence and Interrelationships of Root Surface Caries in Lufa, Papua-New Guinea, Community Dent Oral Epidemiol 2:295-304.

SILNESS, J. and LÖE, H. (1964): Periodontal Disease in Pregnancy. II. Correlation between Oral Hygiene and Periodontal Condition, Acta Odontol Scand 22:121-134.

STAMM, J.S. and BANTING, D.W. (1980): Comparison of Root Caries Prevalence in Adults with Life-long Residence in Fluori- dated and Non-fluoridated Communities, IADR Progr \& Abst 59:No. 552.

SUMNEY, D.L.; JORDAN, H.V.; and ENGLANDER, H.R. (1973): The Prevalence of Root Surface Caries in Selected Populations, $J$ Periodontol 44:500-504.

VEHKALAHTI, M.; RAJALA, M.; TUOMINEN, R.; and PAUNIO, I. (1983): Prevalence of Root Caries in the Adult Finnish Population, Community Dent Oral Epidemiol 11:188-190. 